\title{
Energy balance in healthy elderly women
}

\author{
BY J. J. REILLY'*, A. LORD ${ }^{1}$, V. W. BUNKER ${ }^{2}$, A. M. PRENTICE 3 , \\ W. A. COWARD ${ }^{3}$, A. J. THOMAS ${ }^{1}$ AND R. S. BRIGGS \\ ${ }^{1}$ University Geriatric Medicine Group, Southampton General Hospital, Southampton SO9 4XY \\ ${ }^{2}$ School of Pharmacy and Biomedical Sciences, University of Portsmouth, Portsmouth PO1 207 \\ ${ }^{3} M R C$ Dunn Nutrition Unit, Cambridge CB2 $1 Q L$
}

(Received 15 October 1991-Accepted 10 March 1992)

\begin{abstract}
There is a paucity of data on which to base estimates of the energy requirements of the elderly. In general, ageing appears to be associated with a reduction in energy requirement arising from a reduction in physical activity and loss of fat-free mass. The aim of the present study was to measure the total energy expenditure (TEE), basal metabolic rate (BMR), and energy expended on physical activity (calculated as TEE-BMR) in a group of healthy elderly women living in the community in Southampton. Mean rates of TEE (9.21 (SD 1.48) $\mathrm{MJ} / \mathrm{d}$ ) and energy expended on physical activity (4.12 (SD 1.19) $\mathrm{MJ} / \mathrm{d}$ ) were higher than those observed in some studies of younger adults in the $U K$, and higher than the factors used to estimate the average energy requirement for the elderly. The results suggest that an age-related reduction in energy requirement is not inevitable and support the hypothesis that the effects of ageing on physical activity, body composition, and hence energy requirements, are variable.
\end{abstract}

Energy balance: Ageing: Healthy elderly women

The elderly represent a large group for which demographic trends predict a substantial increase in numbers, and are a group which is at particular risk of nutritional deficiency (Department of Health and Social Security, 1979). Despite this, there is a paucity of data on which to base recommendations of energy requirements in the elderly.

In general, ageing appears to be associated with a reduction in energy requirements. This reduction is a consequence of: (1) a reduction in basal metabolic rate (BMR) due to loss of fat-free mass (FFM) with age (Schock et al. 1963; McGandy et al. 1966), (2) a reduction in the intensity of physical activity or the time spent on physical activity, or both, (McGandy et al. 1966; Cunningham, 1969). In addition, a secular trend towards reduced activity in contemporary life (Prentice et al. 1985) suggests that the energy requirements of most elderly people will be relatively low.

Detailed studies of activity patterns in the elderly in the community (Patrick et al. 1986; Dallosso et al. 1988) have confirmed that for most individuals habitual activity following retirement is low, but have also demonstrated substantial inter-individual variation in activity. Durnin (1983) commented that old age per se is unlikely to have the same effects on energy requirements and body composition in all individuals and suggested that the energy cost of remaining active in old age may be high relative to that in younger adults.

The aim of the present study was to measure the total energy expenditure (TEE) and energy expended on activity in a group of healthy elderly women using the doubly-labelled water (DLW) method in combination with measurement of resting energy expenditure. These techniques are the only means available for such investigations in individuals living undisturbed lives in the community, and they have been used in several population groups

* Present address: University Department of Human Nutrition, Yorkhill Hospitals, Glasgow G3 8SJ. 
(Prentice et al. 1985, 1986; Livingstone et al. 1990; Davies et al. 1991), though not in the elderly.

\section{METHODS}

Subjects

Eleven apparently healthy elderly women who live independently in the community in Southampton were recruited to the study. All subjects gave their informed consent to the procedures described here, and the research was approved by the Southampton Joint Ethical Sub-Committee.

Information on each subject is given in Table 1, with the omission of one of the subjects who was unable to keep a satisfactory record of food intake and did not comply adequately with the urine sampling schedule necessary for the DLW method.

All subjects were examined by a physician and provided a blood sample for biochemical and haematological investigations. All were in good health: seven had no medical complaints and were taking no medication; three suffered mild and occasional symptoms of arthritis and used analgesics as necessary (Paracetamol, Ibuprofen) but took no other medication.

\section{Body composition}

Body weight was measured to $0 \cdot 1 \mathrm{~kg}$ in light indoor clothing at the beginning and end of the 14-18 d experimental period on the same set of portable scales. Total body water was assumed to be equal to the dilution space of a loading dose of ${ }^{18} \mathrm{O}$-labelled water, determined by extrapolation of the disappearance plot to zero time. Total body fat (FM) was estimated using the assumption that the proportion of water in FFM is 0.732 . FFM was calculated as body weight minus FM. Table 1 gives the observed body composition of each subject.

FM and FFM were also estimated from the sum of four skinfolds following the method of Durnin \& Womersley (1974). Each skinfold was measured in triplicate and the mean value used, and all measurements were made by the same trained observer. This facilitated comparison of the subjects with a reference population of healthy elderly women (Morgan et al. 1986) in Yorkshire with mean age 73 (range 69-78) years. The study group did not differ significantly from this reference population with respect to age, weight, FM or FFM ( $t$ test, $P>0.05$ ).

\section{Energy intake}

For $3 \mathrm{~d}$ (one weekend, two weekdays) within the 14-18 d study, subjects recorded their food and fluid consumption by weighed dietary inventory using portable scales. The weighing-recording technique was demonstrated to each subject before the $3 \mathrm{~d}$ recording period started and their progress was monitored during the $3 \mathrm{~d}$. Metabolizable energy intake (EI) was calculated from a computerized version of McCance and Widdowson's The Composition of Foods (Paul \& Southgate, 1978).

\section{$B M R$}

BMR was measured on each subject using a portable open-circuit indirect calorimeter with a ventilated hood (Datex Instrumentarium Corporation, Helsinki, Finland) using Weir's (1949) modified formula. Measurements of BMR lasted for 30-45 min and were made at room temperatures of $22-26^{\circ}$ with subjects clothed and in a comfortable supine position. Each measurement was made in the early morning after the subjects had fasted for 8-12 $\mathrm{h}$ (overnight). In each subject BMR was measured twice, with the exception of subject no. 8 (measured once). The mean of the two measurements was used and is presented in Table 2. Differences between first and second measurements were slight (mean difference, 
Table 1. Anthropometric characteristics of subjects

\begin{tabular}{|c|c|c|c|c|c|c|}
\hline \multirow{2}{*}{$\begin{array}{l}\text { Subject } \\
\text { no. }\end{array}$} & \multirow{2}{*}{$\begin{array}{c}\text { Age } \\
\text { (years) }\end{array}$} & \multirow{2}{*}{$\begin{array}{l}\mathrm{Wt} \\
(\mathrm{kg})\end{array}$} & \multirow{2}{*}{$\begin{array}{l}\text { Fat-free mass* } \\
\qquad(\mathrm{kg})\end{array}$} & \multirow{2}{*}{$\begin{array}{l}\text { Fat mass* } \\
\qquad(\mathrm{kg})\end{array}$} & \multicolumn{2}{|c|}{ Percentage fat mass estimated from: } \\
\hline & & & & & Total body water & Skinfolds \\
\hline 1 & 71 & $60 \cdot 2$ & $39 \cdot 9$ & $20 \cdot 3$ & $33 \cdot 7$ & $33 \cdot 0$ \\
\hline 2 & 72 & $56 \cdot 2$ & $35 \cdot 4$ & $20 \cdot 8$ & $37 \cdot 0$ & $31 \cdot 0$ \\
\hline 3 & 68 & $71 \cdot 2$ & $45 \cdot 2$ & $26 \cdot 0$ & $36 \cdot 5$ & $33 \cdot 5$ \\
\hline 4 & 71 & $63 \cdot 8$ & $39 \cdot 1$ & $24 \cdot 7$ & $38 \cdot 7$ & $35 \cdot 0$ \\
\hline 5 & 74 & $61 \cdot 1$ & $39 \cdot 5$ & $21 \cdot 6$ & $35 \cdot 4$ & $34 \cdot 2$ \\
\hline 6 & 79 & $43 \cdot 8$ & $29 \cdot 4$ & $14 \cdot 4$ & $32 \cdot 9$ & $30 \cdot 0$ \\
\hline 7 & 77 & $65 \cdot 6$ & $37 \cdot 9$ & $27 \cdot 7$ & $42 \cdot 3$ & $35 \cdot 0$ \\
\hline 8 & 70 & $62 \cdot 4$ & $43 \cdot 5$ & 18.9 & $30 \cdot 3$ & 34.8 \\
\hline 9 & 73 & $58 \cdot 3$ & $35 \cdot 1$ & $23 \cdot 2$ & $39 \cdot 8$ & $38 \cdot 0$ \\
\hline 10 & 73 & 57.7 & $38 \cdot 0$ & $19 \cdot 7$ & $34 \cdot 2$ & $35 \cdot 0$ \\
\hline Mean & 73 & $60 \cdot 0$ & $38 \cdot 3$ & $21 \cdot 7$ & $36 \cdot 1$ & $34 \cdot 0$ \\
\hline SD & 3 & $72 \cdot 2$ & $4 \cdot 4$ & 3.9 & $3 \cdot 6$ & $2 \cdot 3$ \\
\hline
\end{tabular}

* Estimated from total body water.

ignoring direction of error, was $2 \cdot 9$ (range $0 \cdot 1-7 \cdot 2$ ) \%. The instrument was calibrated using the manufacturer's instructions and validated periodically by infusion of a test gas of known composition $\left(\mathrm{N}_{2}-\mathrm{CO}_{2}(80: 20, \mathrm{v} / \mathrm{v})\right)$ at measured rates of flow in order to simulate physiological rates of $\mathrm{O}_{2}$ consumption and $\mathrm{CO}_{2}$ production.

\section{TEE}

TEE was measured using the DLW method from the differential disappearance of water labelled with deuterium and ${ }^{18} \mathrm{O}$ from body water. Subjects provided a predose baseline urine specimen and were then given an oral loading dose of $1.6 \mathrm{ml} \mathrm{H}_{2}{ }^{18} \mathrm{O} / \mathrm{kg}$ (approximately 10\% enriched with ${ }^{18} \mathrm{O}$ ) which was mixed with $0.06 \mathrm{ml} 99.8 \%$ deuterium oxide $/ \mathrm{kg}$. Subjects then collected a single urine specimen each day for $14-18 \mathrm{~d}$ and recorded the time of each collection.

Samples were analysed for deuterium and ${ }^{18} \mathrm{O}$ using a VG Aqua-Sira dual-beam isotoperatio mass spectrometer (VG Isogas, Middlewich, Cheshire), and rate-constants and dilution spaces were calculated using the Cambridge multi-point system (Coward, 1988).

The proportion of water turnover which was fractionated was calculated as described previously (Prentice, 1988), and averaged 26.4 (SD 4.3)\%. Estimated $\mathrm{CO}_{2}$ production was converted to heat production from the observed food quotient, as described elsewhere (Black et al. 1986). Details of the principles, calculation of results and estimates of error associated with the technique have been published elsewhere (Coward, 1988; Prentice, 1988). The standard error of the estimates of $\mathrm{CO}_{2}$ production averaged 3.3 (range $0 \cdot 6-6 \cdot 3) \%$.

The amount of energy expended on activity plus thermogenesis was calculated as TEE minus BMR. The ratio TEE:BMR, also known as the physical activity level (PAL), was used as a relative index of activity for comparison within the group and with other studies.

\section{Physical activity questionnaire}

All subjects recorded physical activity for what they considered to be a typical day during the 14-18d experimental period. The questionnaire was a modified version of that previously published (Dallosso et al. 1988) and was based on the self assessment of time spent walking, standing, on productive activity (indoor and outdoor), physically active 
leisure, and 'muscle loading activity' (using stairs, load carrying). In addition, subjects were asked to assess the intensity of activity in the latter three categories, and their frequency, during one of the weeks of the study. The questionnaire was administered by the same interviewer who sought justification of the rationale for the sample day chosen as 'typical' from each subject before proceeding. The validity and reliability of the questionnaire had been assessed previously (Dallosso et al. 1988). Subjects were then assigned scores based on the activity questionnaire and were rank-ordered from lowest to highest activity levels.

\section{RESULTS}

EI

The mean apparent EI (Table 2) was 6.71 (SD 1.29) MJ/d (1604 (SD 308) kcal/d).

\section{$B M R$}

BMR averaged 5.11 (SD 0.38) MJ/d (1221 (SD 91) kcal/d). Predicted (Committee on Medical Aspects of Food Policy, 1991) and measured BMR values are given in Table 2.

\section{$T E E$}

Total energy expenditure averaged 9.21 (SD 1.48) MJ/d (2201 (SD 354) kcal/d); 155 (SD 25 ) $\mathrm{kJ} / \mathrm{kg}$ per d and 242 (SD 36) $\mathrm{kJ} / \mathrm{kg}$ FFM per d (Table 2).

\section{Energy cost of physical activity}

The energy expended on activity plus thermogenesis is given for each subject in Table 2 . This ranged from 2.64 to $5.73 \mathrm{MJ} / \mathrm{d}$ with a mean of $4.12 \mathrm{MJ} / \mathrm{d}(985 \mathrm{kcal} / \mathrm{d})$.

The mean PAL was 1.80 (range 1.53-2.06; Table 2).

\section{Physical activity questionnaire}

The questionnaire scores ranged from 13 to 37 arbitrary units (Table 2). Questionnaire score was significantly correlated with PAL $(r 0.77 ; P<0.01)$ suggesting broad agreement within the group between the objective activity assessment and the energy expended on physical activity.

\section{DISCUSSION}

This is the first report of measurements of TEE and the energy expended on physical activity in the elderly in the community using DLW. The literature contains a few reports of TEE in elderly subjects, all from studies conducted before 1970 (Von Wirths, 1963; Durnin, 1978) using time-activity budgets. The validity of the time-activity budget method is questionable (Durnin, 1984), and the fact that these studies investigated elderly subjects who worked in heavy manual occupations limits their relevance to considerations of the energy requirements of the retired elderly in the UK today. However, these reports did demonstrate that estimates of the TEE of the elderly appeared to be at least as high as those of younger adults in similar occupations, when studied by the same methods (Durnin, 1983).

The subjects in the present study represented a healthy, self-selected, and highly motivated group. As such, they cannot be regarded as a representative sample of the retired elderly in the community, but there is no evidence that they represent an aberrant group of individuals. Comparison with the most suitable reference population (Morgan et al. 1986) available revealed no marked differences in age or body weight or composition. In fact, the similarity between the study group and the reference population is striking.

TEE exceeded apparent EI in all subjects (Table 2) yet all subjects were in energy balance during the study (as indicated by serial weighing and skinfold thickness measurement). This 
Table 2. Rates of energy intake and expenditure in healthy elderly women living independently in the community*

\begin{tabular}{|c|c|c|c|c|c|c|c|c|}
\hline \multirow{2}{*}{$\begin{array}{l}\text { Subject } \\
\text { no. }\end{array}$} & \multirow{2}{*}{$\begin{array}{c}\mathrm{EI} \\
(\mathrm{MJ} / \mathrm{d})\end{array}$} & \multirow{2}{*}{$\begin{array}{c}\text { TEE } \\
(\mathrm{MJ} / \mathrm{d})\end{array}$} & \multicolumn{2}{|c|}{$\operatorname{BMR}(\mathrm{MJ} / \mathrm{d})$} & \multirow{2}{*}{$\begin{array}{c}\text { TEE } \\
(\mathrm{kJ} / \mathrm{kg} \text { per } \mathrm{d})\end{array}$} & \multirow{2}{*}{$\begin{array}{c}\text { TEE-BMR } \\
(\mathrm{MJ} / \mathrm{d})\end{array}$} & \multirow[b]{2}{*}{ PAL } & \multirow{2}{*}{$\begin{array}{c}\text { Activity } \\
\text { scoref }\end{array}$} \\
\hline & & & Measured & Predicted $\dagger$ & & & & \\
\hline 1 & $8 \cdot 86$ & $9 \cdot 38$ & $5 \cdot 37$ & $5 \cdot 20$ & 156 & 4.01 & $1 \cdot 74$ & 26 \\
\hline 2 & 5.57 & $7 \cdot 42$ & $4 \cdot 71$ & $5 \cdot 04$ & 132 & $2 \cdot 71$ & $1 \cdot 57$ & 13 \\
\hline 3 & $8 \cdot 50$ & $9 \cdot 41$ & $5 \cdot 42$ & 5.62 & 132 & 3.99 & $1 \cdot 74$ & 23 \\
\hline 4 & 6.84 & $11 \cdot 20$ & $5 \cdot 47$ & $5 \cdot 34$ & 177 & $5 \cdot 73$ & $2 \cdot 04$ & 20 \\
\hline 5 & $7 \cdot 51$ & $8 \cdot 37$ & $4 \cdot 71$ & $5 \cdot 23$ & 138 & 3.66 & 1.79 & 19 \\
\hline 6 & 6.77 & $7 \cdot 43$ & $4 \cdot 62$ & $4 \cdot 41$ & 168 & $2 \cdot 81$ & 1.61 & 26 \\
\hline 7 & $5 \cdot 77$ & $7 \cdot 53$ & $4 \cdot 89$ & $5 \cdot 30$ & 115 & $2 \cdot 64$ & 1.53 & 13 \\
\hline 8 & $5 \cdot 20$ & $10 \cdot 30$ & $5 \cdot 41$ & $5 \cdot 28$ & 166 & 4.89 & 1.91 & 26 \\
\hline 9 & 5.27 & $10 \cdot 10$ & $4 \cdot 87$ & $5 \cdot 13$ & 174 & $5 \cdot 23$ & $2 \cdot 06$ & 34 \\
\hline 10 & 6.82 & $11 \cdot 14$ & $5 \cdot 58$ & $5 \cdot 10$ & 193 & $5 \cdot 56$ & 1.98 & 37 \\
\hline Mean & $6 \cdot 71$ & $9 \cdot 21$ & $5 \cdot 11$ & $5 \cdot 17$ & 155 & $4 \cdot 12$ & $1 \cdot 80$ & \\
\hline SD & 1.29 & 1.48 & $0 \cdot 38$ & 0.31 & 25 & $1 \cdot 19$ & $0 \cdot 19$ & \\
\hline
\end{tabular}

EI, metabolizable energy intake; BMR, basal metabolic rate; TEE, total energy expenditure; TEE-BMR, energy expended on physical activity plus thermogenesis; PAL, TEE:BMR

* For details of subjects, see Table 1 .

$\dagger$ Obtained from published equations for this age-group (Committee on Medical Aspects of Food Policy, 1991).

\# Activity score in arbitrary units designed to provide an objective assessment of physical activity which could be used to rank order activity within the group.

raised the question of the validity of the methodology for measurement of EI and expenditure. The DLW method has been repeatedly validated (Schoeller, 1988), has no appreciable bias (Coward, 1988; Prentice, 1988; Schoeller, 1988) and a precision of approximately $5 \%$ (Schoeller, 1988). DLW, therefore, represents a suitable reference method against which measurement of EI can be compared. Several studies have identified discrepancies between apparent EI and energy expenditure in subjects who are in energy balance (Livingstone et al. 1990; Schoeller, 1990; Mertz et al. 1991), with underestimation of EI being the usual finding. The design of the present study was such that it is not possible to identify the relative contribution of the factors which might lead to underestimation of habitual intake, i.e. under-reporting of consumption, under-eating during the measurement period, imprecision in the estimate of EI from the $3 \mathrm{~d}$ record. It is clear that the estimates of EI obtained are unphysiological as estimates of the habitual EI of subjects in energy balance; the ratio of EI : BMR ranged from 0.96 to 1.65 and in six of ten cases was less than 1.27 which is taken to be the lower limit of feasibility for free-living subjects (Food and Agriculture Organization/World Health Organization/United Nations University, 1985).

The most important finding of the present study is that the observed rates of TEE are higher than expectations. The new dietary reference value for energy is based on an assumed PAL for sedentary subjects of 1.5 (Committee on Medical Aspects of Food Policy, 1991). The observed mean PAL here was 1.80 with the lowest value being 1.54 (Table 2 ). These relatively high rates of energy expenditure in physical activity are consistent with our observations on the activity of the subjects. The activity questionnaire suggested that the subjects were more physically active than the mean of a large random sample of women of similar age in Nottingham (Dallosso et al. 1988). For example, the estimated mean timeperiod spent on active leisure was 4.7 (range $0.5-13.6$ ) $\mathrm{h} /$ week, and the mean time-period spent walking was 10.2 (range $1.5-22.0$ ) h/week. Comparable mean values from the study in Nottingham were 1.8 and $6.4 \mathrm{~h}$ respectively. 
Some of the subjects were very active by any standards. For example, subjects nos. 9 and 10 reported respectively 1.3 and $1.9 \mathrm{~h} / \mathrm{d}$ in physically active leisure pursuits (aerobic exercise classes, swimming, cycling, tennis).

The observed expenditure on physical activity was higher than in previous reports on younger adults in the UK, such as lean and obese women in Cambridge (Prentice et al. 1985,1986 ), but is similar to that observed in a mixed group of younger adults in Northern Ireland (Livingstone et al. 1990), and in children and adolescents in Cambridge and Northern Ireland (Davies et al. 1991). The observed rates of energy expenditure are considerably higher than those reported in a group of psychogeriatric patients (Prentice et al. 1988), and in a group of elderly inpatients we studied recently (Reilly et al. 1992).

One point which is relevant to such comparisons concerns the interpretation of differences in PAL between groups. The PAL is calculated as TEE: BMR and as such both the BMR and TEE must be considered. In elderly subjects the loss of FFM and relative (or absolute) expansion of FM means that the BMR is reduced relative to that of younger adults. If physical activity were to remain constant this would raise the PAL with advancing age. In practice, if physical activity were to remain constant the energy cost of that activity would probably not remain constant but increase, if only because of the extra cost of movement with a reduced FFM and expanded FM. Indeed there is some empirical evidence that the energy cost of standardized physical activity is increased in elderly subjects (Durnin, 1983; Bassey \& Terry, 1986). Since we can find no evidence of serious bias in our measurements of TEE and BMR, our estimates of PAL, as defined previously, must remain, but with the caveat that the interpretation of these PAL values requires some caution: PAL may be artifactually raised in elderly subjects.

The present study, therefore, provides no evidence that the energy requirements of healthy, active elderly women are low, but is further evidence that the effect of ageing on body composition, activity, and hence energy requirements is variable (Durnin, 1983). Physical activity may also stimulate food intake. Low food intake is the major cause of nutrient deficiency in the elderly (Department of Health and Social Security, 1979; Morgan et al. 1986), and probably contributes to the marked differences in body composition which exist within the elderly population (Morgan et al. 1986). Maintenance of physical activity in old age may have other benefits. These include improved cardiovascular function and protection from a variety of pathological conditions including osteoporosis.

The authors acknowledge the help of Peter Murgatroyd, Susan Jebb, Edgar Pullicino, Alison Black and Rhoda Sutherland. They also thank the volunteers for their co-operation, and an anonymous reviewer for comments on the manuscript. The work was supported by Research Into Ageing, and Cow and Gate Limited.

\section{REFERENCES}

Bassey, E. J. \& Terry, A. M. (1986). The oxygen cost of walking in the elderly. Joumal of Physiology 373, $42 \mathrm{P}$. Black, A. E., Prentice, A. M. \& Coward, W. A. (1986). Use of food quotients to predict respiratory quotients for the doubly-labelled water method of measuring energy expenditure. Human Nutrition Clinical Nutrition 40, $381-391$.

Committee on Medical Aspects of Food Policy (1991). Panel on Dietary References Values for Food Energy and Nutrients for the UK. London: H.M. Stationery Office.

Coward, W. A. (1988). The doubly labelled water method: principles and practice. Proceedings of the Nutrition Society 47, 209-218.

Cunningham, D. A. (1969). Physical activity at work and leisure as related to occupation. Medicine and Sports Science 1, 165-170.

Dallosso, H. M., Morgan, K., Bassey, E. J., Ebrahim, S. B. J., Fentem, P. H. \& Arie, T. H. D. (1988). Levels of customary physical activity among the old and very old living at home. Journal of Epidemiology and Community Health 42, $121-127$. 
Davies, P. S. W. D., Livingstone, M. B. E., Prentice, A. M., Coward, W. A., Jagger, S. E., Stewart, C., Strain, J. J. \& Whitehead, R. G. (1991). Total energy expenditure during childhood and adolescence. Proceedings of the Nutrition Society 50, 14A.

Department of Health and Social Security (1979). Nutrition and Health in Old Age. Report on Health and Social Subjects no. 16. London: H.M. Stationery Office.

Durnin, J. V. G. A. (1978). Nutrition. In Textbook of Geriatric Medicine and Gerontology, [J. C. Brocklehurst, editor]. Edinburgh: Churchill Livingstone.

Durnin, J. V. G. A. (1983). Body composition and energy expenditure in elderly people. Bibliotheca Nutrieta Dieta 33, 16-30.

Durnin, J. V. G. A. (1984). Some problems in assessing the role of physical activity in the maintenance of energy balance. In Energy Intake and Activity, [E. Pollitt and P. Amante, editors]. New York: Alan R. Liss Incorporated Press.

Durnin, J. V. G. A. \& Womersley, J. (1974). Body fat assessed from total body density and its estimation from skinfold thickness: Measurements on 481 men and women aged from 16 to 72 years. British Journal of Nutrition 32, 77-97.

Food and Agriculture Organization/World Health Organization/United Nations University (1985), Energy and Protein Requirements. Technical Report Series no. 724. Geneva: WHO.

Livingstone, M. B. E., Prentice, A. M., Strain, J. J. \& Coward, W. A. (1990). Accuracy of weighed dietary records in studies of diet and health. British Medical Journal 300, 708-712.

McGandy, R. B., Barrows, C. H., Spanias, A., Meredith, A., Store, J. L. \& Norris, A. H. (1966). Nutrient intakes and energy expenditure in men of different ages. Journal of Gerontology 21, 581-587.

Mertz, W., Tsui, J. C., Judd, J. T., Reiser, S., Hallfrisch, J., Morris, E. R., Steele, P. D. \& Lashley, E. (1991). What are people really eating? American Journal of Clinical Nutrition 54, 291-295.

Morgan, D. B., Newton, H. M. V., Schorah, C. J., Jewitt, M. A., Hancock, M. R. \& Hullin, R. P. (1986). Abnormal indices of nutrition in the elderly: a study of different clinical groups. Age and Ageing 15, 65-76.

Patrick, J. M., Bassey, E. J., Irving, J. M., Blecher, A. \& Fentem, P. H. (1986). Objective measurements of customary physical activity in elderly men and women before and after retirement. Quarterly Journal of Experimental Physiology 71, 47-58.

Paul, A. A. \& Southgate, D. A. T. (1978). McCance and Widdowsons's The Composition of Foods. London: H.M. Stationery Office.

Prentice, A. M. (1988). Applications of the doubly-labelled water technique in free-living adults. Proceedings of the Nutrition Society 47, 259-268.

Prentice, A. M., Black, A. E., Coward, W. A., Davies, H. L., Goldberg, G. R., Murgatroyd, P. R., Ashford, J., Sawyer, M. \& Whitehead, R. G. (1986). High levels of energy expenditure in obese women. British Medical Journal 292, 983-987.

Prentice, A. M., Coward, W. A., Davies, H. L., Murgatroyd, P. R., Black, A. E., Goldberg, G. R., Ashford, J., Sawyer, M. \& Whitehead, R. G. (1985). Unexpectedly low levels of energy expenditure in healthy women. Lancet i, 1419-1422.

Prentice, A. M., Leavesley, K., Murgatroyd, P. R., Schorah, C. J., Coward, W. A. \& Blaydon, P. (1988). Is severe wasting in elderly mental patients caused by an excessive energy requirement? Age and Ageing 18, $158-167$.

Reilly, J. J., Lord, A., Bunker, V. W., Prentice, A. M., Coward, W. A., Thomas, A. J. \& Briggs, R. S. (1992). Energy balance and physical activity in healthy and chronically ill elderly women. Age and Nutrition 3, 121-122.

Schoeller, D. A. (1988). Measurement of energy expenditure in free living humans using doubly-labelled water. Journal of Nutrition 47, 209-218.

Schoeller, D. A. (1990). How accurate is self reported dietary intake? Nutrition Reviews 48, 373-379.

Shock, N. W., Watkins, D. M. \& Yiengst, M. J. (1963). Age differences in the water content of the body as related to basal oxygen consumption in males. Journal of Gerontology 18, 1-8.

Weir, J. B. (1949). New methods for calculating metabolic rate with special reference to protein metabolism. Journal of Physiology 109, 1-9.

Von Wirths, W. (1963). Die relation van arbeits- und grundurnsatz zum gesamtumsatz bei alteren personen mit kosperlicher belastung. (The relationship of working and basal metabolic rate to total metabolic rate in elderly people in physical exercise.) Gerontologia 8, 209-232. 